\title{
ESTRATÉGIAS DE FRAGMENTAÇÃO NO CINEMA CONTEMPORÂNEO: SHORT CUTS: CENAS DA VIDA, DE ROBERT ALTMAN, E ELEFANTE, DE GUS VAN SANT
}

\author{
Strategies of fragmentation in the contemporary cinema: Short Cuts by Rrobert \\ Altman and Elephant by Gus Van Sant
}

\author{
Estrategias de fragmentatión en el cine contemporáneo: Short Cuts, de Robert \\ Altman, y Elephant, de Gus Van Sant
}

Barbara Cristina Marques

Universidade Estadual de Londrina (UEL)

barbara.marques@gmail.com

Henrique Codato

Universidade Fortaleza (UNIFOR)

picega@hotmail.com

\section{Resumo}

O cinema contemporâneo tem exibido, com considerável frequência, obras cuja estrutura narrativa se revela quebrada, descontínua e dispersa. Observa-se, nesse tipo de cinema, a subtração ou a desativação do fluxo narrativo, da linearidade narrativa, o que vem a promover novas formas de experiência fílmica. Nesse sentido, apresentamos uma breve análise de duas produções norte-americanas - Short Cuts: cenas da vida (Robert Altman, 1993) e Elefante (Gus Van Sant, 2003) - a fim de apontar, na escritura desses filmes, exemplos de estratégias de fragmentação e os diferentes sentidos que tal iniciativa possibilita construir.

Palavras-chave: Cinema contemporâneo. Robert Altman. Gus Van Sant.

\begin{abstract}
Contemporary cinema has often shown films whose structure is remarkably broken, discontinuous and dispersive. We observe in this kind of cinema the subtraction or even the deactivation of the narrative flow, its linearity, which promotes new kinds of experience. Thereby, we present a brief analysis of two American films - Short Cuts (Robert Altman, 1993) and Elephant (Gus Van Sant, 2003) - trying to indicate trough the film's scripture some examples of these strategies of fragmentation, noticing, as well, the different senses that this initiative can promote.
\end{abstract}

Keywords: Contemporary cinema. Robert Altman. Gus Van Sant. 


\section{Resumen}

El cine contemporáneo ha exhibido, con considerable frecuencia, obras cuya estructura narrativa se revela quebrada, discontinua y dispersa. Se observa, en este tipo de cine, la sustracción o la desactivación del flujo narrativo, de la linealidad narrativa, lo que viene a promover nuevas formas de experiencia fílmica. En ese sentido, presentamos un breve análisis de dos producciones norteamericanas - Short Cuts (Robert Altman, 1993) y Elefante (Gus Van Sant, 2003) - a fin de apuntar, en la escritura de esas películas, ejemplos de estrategias de fragmentación y los diferentes sentidos que tal iniciativa permite construir.

Palabras clave: Cine contemporâneo. Robert Altman. Gus Van Sant.

\section{INTRODUÇÃO}

Um dos traços mais característicos das narrativas fílmicas contemporâneas é o modo pelo qual elas desarticulam tempo e espaço, promovendo, com isso, uma quebra da linearidade. Diferentemente do cinema narrativo dito clássico, que pressupunha uma sequencialidade, uma organização espaciotemporal sempre condicionada ao ponto de vista de um observador onipresente e onisciente, as narrativas contemporâneas trabalham com a existência simultânea de diversos elementos capazes de agenciar o espaço e o tempo diegéticos por meio de estratégias no âmbito da narratividade, suspendendo, desse modo, a logicidade com a qual estávamos habituados.

Como explica Sandro Bernardi (2012), essa passagem de um cinema a outro é marcada por uma nova topologia do olhar do espectador, que migra do centro da representação para sua periferia. Esse deslocamento provoca, sem dúvidas, uma importante transformação na compreensão daquilo que se passa em cena. Mas se isso acontece, diz o autor, não é porque tal centro se encontraria em outro lugar, alhures ao filme; mas, sim, em virtude de uma multiplicidade de centros, de olhares e de pontos de vista e de escuta possíveis que esse novo cinema faz surgir. Para Bernardi (2012), o problema estético vem tornar-se, um problema ético, pois concerne à própria posição do homem no mundo.

As discussões de Gilles Deleuze, que ocuparam desde meados da década de $1980^{1}$ um lugar importante nos estudos cinematográficos, ao tratar da "crise da imagem-ação", tendo em vista o desarranjo das narrativas fílmicas modernas, são um ponto de referência bastante significativo no que tange à observação de um tipo de cinema que constrói outros 'modelos' compositivos relativos à organização da estrutura narrativa.

1 Com a publicação de Cinema I - L'image-mouvement e Cinema II - L'image-temps. 
Nasce uma nova espécie de imagem, que podemos tentar identificar no cinema americano do pós-guerra, fora de Hollywood. Em primeiro lugar, a imagem não remete mais a uma situação globalizante ou sintética, mas dispersiva. Os personagens são múltiplos, com inferências fracas, e se tornam principais ou voltam a ser de novo secundários. No entanto, não se trata de uma série de sketches ou de uma sucessão de episódios, pois todos eles são apreendidos na mesma realidade que os dispersa. Robert Altman explora esta direção em Cenas de um casamento e sobretudo em Nashville, com pistas sonoras múltiplas e tela amórfica que permite várias mises-enscène simultâneas (DELEUZE, 1985, p. 230-231).

Percebe-se, a partir disso, que as narrativas fílmicas contemporâneas alcançaram essa simultaneidade em parte por conta da quebra do relato e da estrutura, valendo-se do fragmento como elemento indispensável no trato compositivo da obra. As consequências desse gesto de 'desmontar' as sequências da narração geram, na maioria das vezes, certa indeterminação semântica e acabam por convocar o espectador a outros modos de participação na experiência do filme, como defendemos.

Short Cuts: cenas da vida, de Robert Altman (1993), e Elefante, de Gus Van Sant (2003), são bons exemplos desse tipo de cinema. Não se trata, aqui, da tentativa de comparar essas duas obras, tão diferentes entre si. É certo que cada uma delas se utiliza de estratégias bastante distintas e particulares no que se refere ao desmonte da narrativa. Acreditamos, entretanto, que ambas servem para ilustrar esse modo de agenciamento mediante, entre outros artifícios, a dilatação, o encurtamento e a fragmentação de suas respectivas dimensões espaciotemporais, como tentaremos mostrar a seguir.

\section{A NARRATIVA AOS PEDAÇOS EM SHORT CUTS}

Baseado em nove contos e um poema - "Lemonade", do escritor norte-americano Raymond Carver (1938-1988) -, Short Cuts reúne diferentes fios diegéticos a alternarem-se em intervalos regulares que mostram, durante pouco mais de três horas de filme, a vida de nove famílias americanas (ao todo, 22 personagens) no período de quatro dias. A câmera de Altman invade a intimidade de cada um desses núcleos, se deslocando rapidamente entre uma intriga e outra. As inúmeras mudanças de cena, sempre dadas por cortes abruptos, movimento que exige do espectador vigilância permanente, impõem à narração um ritmo quase alucinante. O filme insiste nos jogos elípticos e o espectador nem sempre é capaz de acompanhar a sequência narrativa de todos os acontecimentos. É preciso (re)montar (a partir 
dos fragmentos da própria montagem do filme) e (re)encadear os eventos a fim de compreender todas as histórias.

Em narrativas multiplots, como Short Cuts, em que todos os caminhos se bifurcam, a complexidade aparece justamente no modo como se processa o agenciamento de todas as unidades que se mostram desconexas a princípio, mas que, ao final, estão absolutamente amarradas por vários tipos de associação. Há uma espécie de variação de percurso para a maneira como os enredos vão se cruzar. Reconhecemos uma situação inicial que move a trama, mas ela se perde no caminhar da narração, e o espectador, por sua vez, também acaba se perdendo na intimidade de cada enredo.

Os personagens em Short Cuts apenas se cruzam, não estabelecem relações para além daquelas já existentes, como a amizade entre os Bush e os Kaiser, por exemplo. O filme, nesse aspecto, potencializa a incomunicabilidade das relações, temática central da narrativa do livro de Carver. Desde o início, todos os núcleos diegéticos alternam-se na tela sobre o mesmo fundo, no qual aparecem os helicópteros do governo a pulverizar a cidade de Los Angeles com o veneno malathion. Trata-se de um filme em que praticamente todas as cenas se apresentam de forma alternada, em que se salta de uma história para outra, ficando o espectador encarregado de 'costurar' as ligações entre elas, agenciando e conectando seus fios diegéticos.

Michel Serceau (1999) assevera que Altman não faz uso da montagem alternada (e, algumas vezes, da montagem paralela) apenas para garantir "la continuité narrative de l'ensemble"':

Ce mode traditionnel de présentation simultanée de différentes actions a dans le principe pour rançon la multiplication des ellipses: la perception et la réception de chacune des histoires (et avec elles l'implication que peut y avoir le spectateur) est interrompue: on passe sans solution de continuité, sans motivation dramatique, à une autre action. (SERCEAU in ROMANSKI, 1999 , p. 177) ${ }^{3}$.

É preciso, no entanto, reavaliar essa afirmação do crítico quanto à passagem "sem solução de continuidade" de uma cena à outra, ou de uma história à outra. Em Short Cuts, notamos uma série de recursos capazes de assegurar a continuidade narrativa e a unidade de sentido do filme. Por meio de 'rimas visuais', Altman consegue estabelece analogias ao

\footnotetext{
2 "A continuidade narrativa do conjunto" (Tradução nossa).

${ }^{3}$ Esse modo tradicional de apresentação simultânea de diferentes ações tem como contrapartida a multiplicação das elipses: a percepção e a recepção de cada uma das histórias (e com elas a implicação que pode ter o espectador a seu respeito) são interrompidas: passa-se a uma outra ação sem solução de continuidade, sem motivação dramática”. (Tradução nossa).
} 
combinar, de forma mais ou menos contingente, imagens distintas, no entanto, bastante semelhantes entre si.

É inegável que muitas cenas são cortadas abruptamente, de forma um tanto aleatória. Contudo, defendemos que essas várias interrupções entre cenas ou enredos correspondem à motivação dramática do filme, pois, na maioria das vezes, o fechamento de uma cena - nunca exatamente 'finalizada' - antecipa ou se relaciona com o início da seguinte, independentemente da relação que elas mantêm entre si no avançar da narrativa (se há sucessão ou continuação da anterior, ou se, ao contrário, as cenas se reportam a outro núcleo narrativo, por exemplo). As repetições de alguns elementos, que poderíamos chamar aqui de 'reduplicações', contribuem para o entrecruzamento dos fios diegéticos. Elas geralmente apresentam alguma semelhança estrutural e mostram, quando aproximadas, forte analogia simbólica. Tais imagens surgem, com frequência, associadas ao signo da água, como mostram as figuras a seguir.

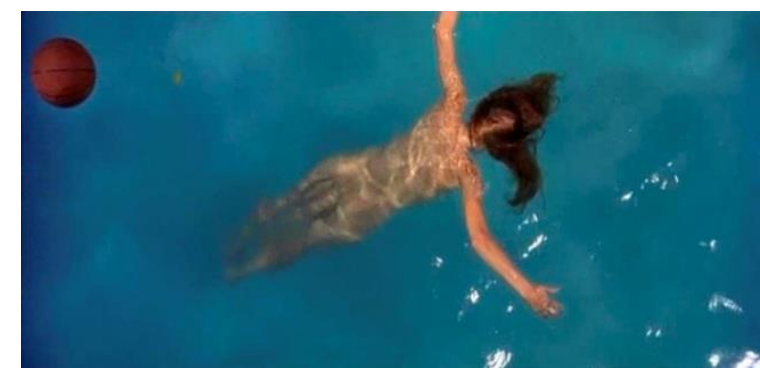

Figura 1

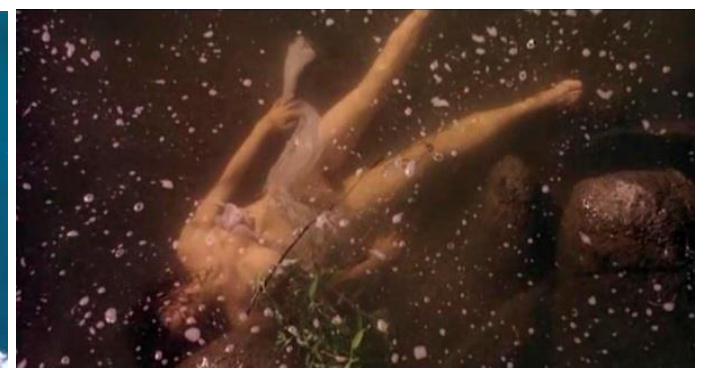

Figura 2

Na Figura 1, vemos a personagem Zoe boiando na piscina de sua casa, fingindo estar morta. A câmera empresta seu olhar ao personagem Jerry, que, por trás da cerca da casa dos Finnigan, observa, como um voyeur, a jovem tirar a roupa e pular na piscina. No mesmo plano surge, na sacada da casa de Zoe, sua mãe - Tess - também a observar a filha e, com um ar de desdém, atirar-lhe um gelo do copo para que ela volte à superfície. Na cena seguinte (Figura 2), muda-se para outro momento do filme, no qual Stuart e seus amigos pescadores estão na beira de um rio, lugar que serve de cenário para o fim de semana dos amigos. Nesse momento do filme, os amigos encontram o corpo sem vida de uma mulher boiando no rio, aparentemente violentada. No plano da visualidade, as duas imagens apresentam uma forte correspondência: duas cenas propositadamente justapostas para marcar a conexão entre as histórias. Zoe, ao longo do filme, não terá contato algum com a moça morta, tampouco com Stuart e seus amigos (muito embora Stuart e Claire, sua esposa, na abertura do filme, estivessem assistindo a um concerto da moça, que é violoncelista). Todavia, Zoe, por vários 
motivos, muitos deles ligados à relação problemática com sua mãe, se suicida no final do filme. Assim, uma vez combinadas, podemos dizer que as duas cenas prenunciam a morte da personagem Zoe, que só vai acontecer mesmo no final do filme. Um paralelismo como esse (capaz de dar ao espectador uma espécie de antevisão dos acontecimentos) faz que o espectador de Short Cuts experimente, repetidas vezes, o que Genette (1979) chama de "prolepse", tendo, em geral, "a função de anunciar um acontecimento de modo mais ou menos explícito" (GAUDREAULT; JOST, 2009, p. 144).

Essas inter-relações entre imagens semelhantes funcionam como um mecanismo metafórico, no plano discursivo-narrativo, e também no plano visual da escritura fílmica. Pode-se afirmar, então, existir uma certa logicidade no que se refere aos modos de articulação da montagem dos planos fragmentados. Essa simbologia da água, remetendo à morte (consumada ou imaginada - como nas fantasias do casal Honey e Bill Bush), volta a aparecer outras vezes no filme.

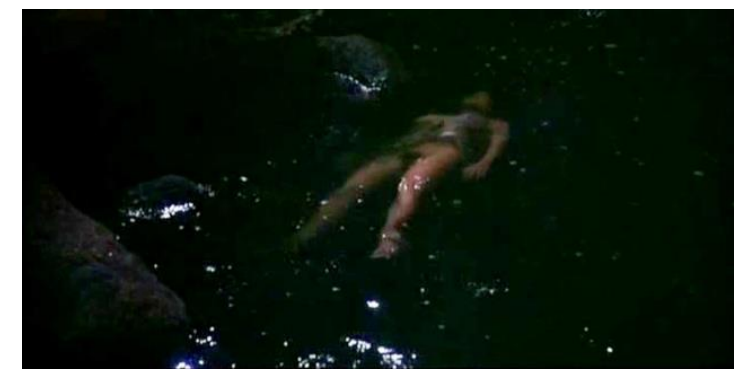

Figura 3

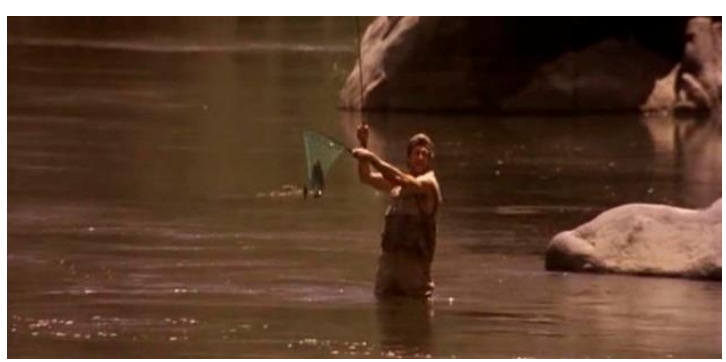

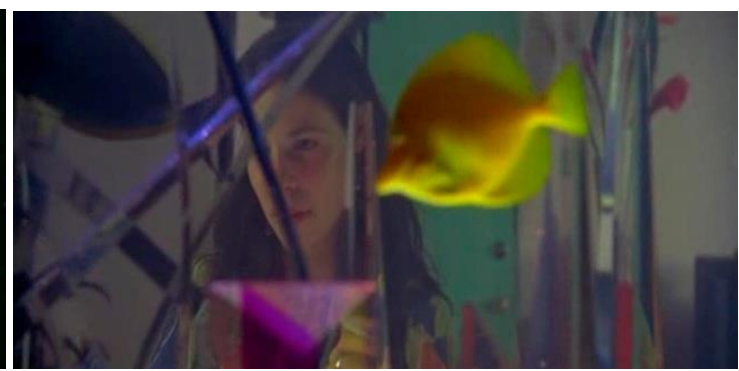

Figura 4

Figura 5

As três figuras acima formam uma sequência do tipo A-B-A; isto é, se estruturam a partir de uma montagem alternada. A primeira cena (Figura 3) mostra novamente o corpo da moça morta no rio, depois de alguns minutos de sua primeira aparição no filme. Na segunda imagem (Figura 4), vemos Honey Bush admirar os peixes do aquário dos vizinhos, quando ela e o marido, o maquiador Bill Bush, vão alimentar os animais durante a ausência dos amigos que partiram em férias. Passamos, portanto, de um enredo ao outro sem qualquer conexão diegética aparente. Cumpre ressaltar que Honey e Bill, em uma espécie de jogo 
sadomasoquista, simulam uma cena de morte que é mostrada ao espectador mediada, justamente, pela transparência da água do aquário e também de um espelho.

Após o corte da cena de Honey e Bill no apartamento dos vizinhos, vemos uma imagem, filmada em plano fixo, na qual Stuart mostra ao amigo, dentro do rio - o mesmo no qual vemos boiar o cadáver da moça - um peixe que acabara de fisgar. Além da relevância com que a água se transforma em artifício metafórico dentro do filme, a figura do peixe também se efetiva como uma imagem de reduplicação nas várias tramas. O peixe do aquário, justamente aquele que encanta Honey, é chamado de peixe-leão, um predador voraz e, pode, nesse caso, ser associado à figura de um tipo de sadismo sexual. Stuart, por exemplo, traz do fim de semana com os amigos algumas trutas que serão o prato principal do jantar que o casal (Stuart e Claire) terá com os Wyman. Isso causa um profundo nojo em Claire, pois ela associa o peixe à imagem da moça morta, que, no fim das contas, tem relação com a brutalidade do assassinato e com a violência sexual sofrida pela jovem. Nesse sentido, há um acento de perversão concentrado na imagem do peixe. Em outra cena ainda, quando Honey vai à casa de Doreen, ela relembra os pequenos abusos sofridos pelo padrasto, Earl. Ao falar disso com sua mãe, vemos Honey depositar em um vidro com água os peixes trazidos do apartamento dos vizinhos.

Podemos apontar, no mesmo sentido, outras tantas reduplicações possíveis de serem traduzidas como conjuntos de relações que se ordenam. Esses elementos atestam a banalidade do cotidiano e, de certa forma, reforçam a temática do filme: mostrar "cenas da vida" de pessoas comuns da classe média californiana. Um dos elementos de maior recorrência no filme diz respeito à onipresença da televisão de modo a assegurar o encadeamento espaciotemporal entre uma trama e outra. A imagem televisiva (em praticamente todas as cenas do filme um aparelho se encontra ligado) serve de contraponto entre um acontecimento grave e a banalização do mesmo. A presença da televisão opera igualmente como um recurso de antecipação dos acontecimentos. Para isso, Altman utiliza as formas publicitárias do pequeno écran a fim de jogar ironicamente com o destino dos personagens. As chamadas publicitárias são estrategicamente apresentadas como metáforas comunicativas para sugerir, antever e prestar comentários acerca dos acontecimentos. A televisão responde, assim, às novas formas de espetacularização da realidade (DEBORD, 1997; SARLO, 1997) e a uma espécie de exibição impudica das emoções dos personagens. Por força da onipresença da televisão, um cotidiano ordenado e previsível ganha corpo, corroborando a sensação de banalidade do filme. 
Nas cenas que mostram o evento mais significativo do filme - o atropelamento do menino Casey -, a inserção das imagens televisas colabora para suspender o efeito de ficção. O espectador assiste, então, a um duplo relato entre aquilo que é mostrado e o que é enunciado pelo aparelho. Depois de ter sido atropelado por Doreen, Casey volta às pressas para a casa. Quando sua mãe, Ann, chega em casa, flagra o menino na sala, já em estado de sonolência. Ann leva o filho para o quarto e o coloca na cama. Casey dorme enquanto ela telefona ao marido - Howard Finnigan, âncora de um famoso jornal televisivo - dizendo não saber o que fazer. Howard pede à esposa que leve Casey imediatamente ao hospital. Nesse momento, a câmera focaliza, em primeiro plano, um copo de leite sobre o criado-mudo que Ann tentara oferecer ao filho, sem sucesso (Figura 6), pois o menino já não mais respondia.

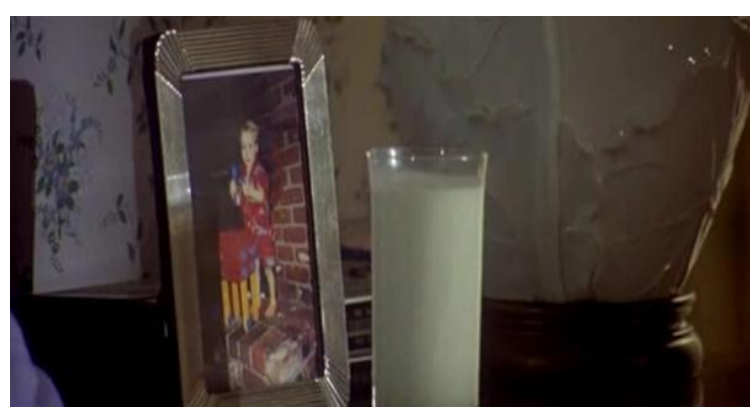

Figura 6

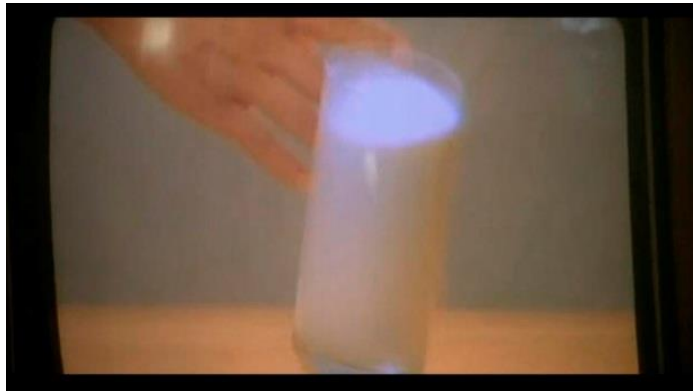

Figura 7

No zoom operado pela câmera sobre o copo de leite, logo que Ann fala com o marido ao telefone, há uma espécie de congelamento da narração da história com o menino Casey. Opera-se, então, um corte e o espectador, numa fração de segundos, é lançado a uma outra cena, aberta com o mesmo zoom, mas que agora focaliza um outro copo de leite, sem, até aquele momento, qualquer relação com os Finnigan (Figura 7). Trata-se de um comercial de televisão em que vemos uma mão esbarrar (aparentemente por azar) num copo de leite e ouvimos a seguinte frase: "Accidents happen every day. Fortunately most are harmless, but some are very serious ${ }^{4 \prime}$. Nesse momento, quem incorpora o papel do narrador é, justamente, a imagem e a voz advindas do anúncio televisivo. Descobrimos, então, que a cena que vemos vem da televisão de Doreen e Earl. Ironicamente, nem um dos dois personagens atentou-se para o comercial, tampouco para a frase enunciada. E, mais ironicamente ainda, Doreen está, em tempo simultâneo à transmissão do comercial, a contar para Earl sobre o atropelamento de Casey.

4 Acidentes acontecem todos os dias. Felizmente, a maioria deles é inofensiva, mas alguns são muito sérios (Tradução nossa). 
Em Short Cuts, o trabalho de montagem exige muitos pontos de conexão por meio de superfícies que sejam significativamente expressivas no processo de sutura de fragmentos e lacunas deixados ao longo da narrativa. A fim de assegurar todos os entrecruzamentos, o diretor não se furta de agudizar e repetir metáforas visuais. Daí a sensação de um certo desgaste da narrativa fílmica diante da abundância de imagens que funcionam como intertextos. Podemos dizer, por conseguinte, que as obviedades performam o grande vetor semântico de Short Cuts. Se de um lado, há uma espécie de protocolo estilístico no uso demasiado de imagens clicherizadas de um cotidiano igualmente clichê, de outro, paradoxalmente, a reduplicação desses recursos provoca um efeito bem interessante: o contraste entre realidade e aparência, entre vida e morte. Como se pudéssemos dizer que de tão familiar, tudo em Short Cuts se torna artificial, instalando-se, na escritura fílmica, um tipo de jogo imagético sem fundo.

\section{O TEMPO DA MORTE EM ELEFANTE}

Em Elefante, Gus Van Sant mostra o cotidiano de uma high school norte-americana momentos antes de uma chacina executada por dois de seus alunos - Alex e Eric - que, num gesto de vingança, invadem o prédio da escola armados até os dentes, atirando à queimaroupa em seus colegas e professores. Como explica Jonathan Rosenbaum (2003), o título do filme remete a uma parábola sobre diversos homens cegos que tentam descrever um elefante, chegando a diferentes conclusões, que variam de acordo com as partes tocadas do corpo do animal $^{5}$. Elefante é também o nome de um curta-metragem dirigido em 1989 por Alan Clarke, sobre a onda de violência que assolou a Irlanda do Norte por meio das ações do Irish Republican Army (IRA). Clarke registra seus personagens com a mesma fascinação que Van Sant filma seus adolescentes: de frente ou de costas, sempre em movimento, num ir e vir constante, matando pessoas sem explicação aparente. Assim, segundo Rosenbaum, ambos os títulos homônimos se referem, de fato, às dificuldades de se ignorar um problema de dimensões tão grandes quanto às de um elefante numa sala de estar, como enuncia um conhecido ditado anglófono ${ }^{6}$.

Elefante é uma obra densa, de ritmo lento, mas certeiro; e ainda que não saibamos exatamente onde ela nos atingirá, dela não saímos ilesos. Boa parte de tal traspassamento

\footnotetext{
${ }^{5}$ Trata-se de uma parábola budista, transformada em poema pelo americano John Godfrey Saxe, cujo título em inglês é "The Blindmen and the Elephant".

${ }^{6}$ The Denial of an Elephant in the livingroom é o que diz o ditado.
} 
acontece em razão da temática do filme e da íntima relação que ele estabelece com o Massacre de Columbine ${ }^{7}$. Não se trata, no entanto, de uma transposição mais ou menos direta do fato para as telas; tampouco há o interesse em encontrar para o evento - real ou filmado algum tipo de explicação, como tenta fazer Michael Moore em Tiros em Columbine (2002), por exemplo. Longe disso, a potência de Elefante deve-se a outros aspectos presentes na materialidade de sua escritura, na singularidade de sua mise-en-scène e na forma pela qual ela convoca o olhar do espectador.

O filme trabalha seu argumento por meio de uma estrutura narrativa fragmentária e lacunar, que desmorona no momento do primeiro tiro. Tal esfacelamento traduz, de partida, a recusa do diretor em apresentar uma visão totalizante da tragédia. Para isso, Van Sant constrói uma obra marcada pela imprecisão espaciotemporal, que avança sob o signo da errância. Ao dispensar a ideia de um senso único de orientação, o tempo que rege a narrativa torna-se um tanto elástico, extensível, quase maleável, permitindo, por conseguinte, também uma multiplicação dos artifícios visuais que compõem o filme.

Podemos dizer que a narrativa se ancora em dois eixos distintos, mas complementares: um primeiro, composto por um arranjo de planos que se encontram e se desencontram no tempo da projeção, a exemplo do que fazem os personagens nos corredores da escola; e, um segundo eixo, marcado pela chacina que irrompe, fornecendo um tempo linear e cronológico ao filme (ainda que preenchido, sem dúvidas, de algumas elipses) e mostrando, por meio de uma sucessão de eventos mais ou menos organizados, o plano de vingança arquitetado por Alex e Eric. É esse segundo eixo, tributário da tragédia $^{8}$, que faz com que a narrativa abandone o tempo da vida - errático, descontínuo e impreciso - em nome de um outro tempo, pontuado pela morte que surge para realinhar/reorganizar a narrativa.

O tempo que antecede a matança parece ser uma espécie de entre-tempo: uma porção de vida na qual nada mais se pode fazer além de viver: caminhar por entre uma sala e outra, abrir e fechar portas, descer e subir escadas, atravessar ambientes. É um 'presente perpétuo', um tempo estendido, vivenciado de forma distinta por cada um dos personagens, que sempre estão a se deslocar no espaço da cena. Já o segundo tempo é um tempo linear e objetivo, que pode ser fracionado, contado, medido. Ele ampara o caráter ficcional do filme, fornecendo-lhe alguma logicidade. Trata-se de um tempo cronometrado, próprio às histórias, às previsões e aos oráculos - o tempo mesmo da ficção. Com essas duas temporalidades absolutamente

7 Episódio corrido no condado de Jefferson, Colorado, Estados Unidos, em 20 de abril de 1999.

${ }^{8}$ Tanto no sentido da tragédia como gênero literário, quanto da tragédia como acontecimento fatídico. 
intrincadas, o filme, então, evita a sucessão causal das cenas, impedindo a construção de uma perspectiva que dê conta de explicar aquilo que vemos em cena. $\mathrm{O}$ massacre encenado não apresenta nem um desfecho preciso (a história é interrompida no curso de seu acontecimento), nem propõe qualquer ação reparatória ou expiatória (a morte ou a punição do assassino, por exemplo). Tal indeterminação transforma-se, certamente, em uma das principais forças motrizes da obra.

Assim, boa parte do filme é conduzido por uma espécie de não-ação; ou melhor: a ação se confunde com a deambulação, com a deriva dos corpos, apanhados em pleno fluxo, tal como o mundo no qual se encontram inseridos. Eles são registrados de muito perto, em tomadas feitas geralmente de frente ou de costas, com uma câmera que os persegue, filmandoos sempre em deslocamento. Ela os acompanha certo tempo e abandona-os em seguida, sem muita cerimônia, para voltar a encontrá-los mais adiante. Desse modo, as sequências parecem avançar em looping - pois cada uma delas refere-se a um personagem distinto -, mas são, de fato, simultâneas no tempo e no espaço. Abrem-se, com isso, a exemplo de Short Cuts, vários fios diegéticos, mas sempre incompletos, diluídos, interrompidos. Essa composição dificulta a apreensão do tempo e do espaço do filme por parte do espectador, que deve refazer mentalmente os percursos dos personagens na tentativa (destarte frustrada) de encontrar alguma coerência para a história.

Sobre os adolescentes protagonistas, sabemos muito pouco: eles nos são apresentados por meio de uma cartela em fundo preto - um plano cego -, no qual figuram seus respectivos nomes escritos em branco. São, ao todo, doze personagens, agrupados em oito blocos distintos (1. John; 2. Elias; 3. Nathan e Carrie; 4. Acadia; 5. Eric e Alex; 6. Michelle; 7. Brittany, Jordan e Nicole; 8. Benny). Além de seus nomes, o que conhecemos deles é fruto de suas conversações pulverizadas com outros personagens, ou, então, daquilo que 'escorrega' de seus cotidianos filmados, sempre de forma contígua, jamais contínua.

A escola de Elefante é um lugar de transição, de passagem. Mas, ainda que os personagens estejam todo tempo em movimento, circulando mais ou menos livremente por essa espécie de labirinto, eles o fazem sempre dentro de um espaço imposto pela câmera, extremamente opressivo, desconectado do resto do mundo através de um sistema visual bastante conceitual e formalista. Esse aspecto geometrizante da escola, filmado através de "uma multiplicidade de linhas verticais, com numerosas portas e janelas que se alongam devido ao rebaixamento do teto, por entre intermináveis corredores" (Saturnino in Scheinfeigel, 2005, p.144) contribui para a criação da atmosfera de clausura. A imagem dos 
jovens é às vezes diminuída em nome da dimensão que o espaço da escola adquire (como na sequência em que vemos Michelle atravessar o ginásio da escola); noutras vezes, os personagens parecem ter sido engolidos pelo quadro, que com seus limites embaralhados, um tanto desfocados, convocam o olhar para aquilo que acontece fora dele. Em certa medida, podemos arriscar dizer que o espaço da escola serve como metáfora para aquilo que se passa no interior desses personagens.

Tendo em vista a imprecisão espaciotemporal que a obra sustenta, nos concentramos na análise de uma sequência específica que condensa esse estranhamento provocado pelo filme. John, Michelle e Elias compõem, juntos, uma das cenas-chave do filme, que mostra, exatamente, uma espécie de 'torção' no tempo da narrativa. É como se a história evoluísse, mostrando o contínuo e o descontínuo dessas vidas filmadas, mas, como uma agulha num disco arranhado, ela tropeçasse, voltando sempre a um mesmo instante já vivido, momento em que o tempo da diegese, de fato, parece sofrer uma suspensão.

Trata-se da cena em que Elias tira uma fotografia de John, no momento exato em que Michelle passa por detrás do fotógrafo, correndo, tentando não ser percebida (Figura 8). Essa mesma cena se repete por três vezes, registradas, cada uma delas, a partir da perspectiva de um dos personagens que dividem a cena. A reiteração aparece, aqui, como figura nuclear, revelando um processo intensificador de significados, mas, de maneira idêntica, ressalta o caráter rotineiro da ação. Não há nenhum aspecto lúdico nela. Nenhum desses três planos que se referem, de fato, a um mesmo instante - traz algum elemento ou aspecto novo à intriga, nem tampouco serve para ancorar as tomadas que o precedem ou sucedem. Supõe-se que eles sejam exatamente iguais, idênticos no que concerne àquilo que se propõem a representar; contudo, isso não é exatamente verdade.

A primeira dessas três sequências começa com a câmera seguindo Elias pela escola, registrando-o de frente, com a imagem distorcida de Michelle, que aparece no fundo do campo filmado (Figura 9). Uma vez que o rapaz tira o retrato de John, a câmera decide acompanhar esse último, que caminha em direção à saída da escola, cruzando com os dois assassinos. Já a segunda sequência também se inicia segundo a perspectiva de Elias; porém, nesse caso, o vemos de costas (Figura 10). Portanto, existe uma inversão de horizonte que se impõe, mostrando, agora, aquilo que antes ocupava o contracampo por meio de um deslocamento do ponto de vista da personagem. O efeito de similaridade, como ressalta Jerôme Peyrel (2003), ocorre em virtude da simetria perfeita dos corredores da escola, captados sob uma mesma angulação. Logo, diz o autor, se a primeira cena funciona a partir do 
princípio da surpresa - provocada pela presença de Alex e Eric, personagens que, até esse momento do filme, não conhecíamos -, a segunda opera a partir da ideia da lembrança, convocando o espectador a se recordar que o massacre está prestes a começar.

Ainda segundo Peyrel (2003), a sequência em que seguimos Michelle é diferente. Nela, toda a área de visão da garota é marcada por uma falta total de nitidez, possibilitada por um trabalho de profundidade de campo, que impõe, por sua vez, uma terceira forma de percepção da cena pelo espectador (Figura 11). Se, nos dois primeiros casos, nós seguíamos os personagens em perspectiva externa, ainda que bastante próxima, nesse terceiro exemplo, a falta de nitidez do entorno faz com que assumamos o lugar de Michelle (ainda que a câmera não seja exatamente subjetiva), identificando-nos à percepção da moça. Tal efeito reforça a sensação de isolamento e de retraimento do personagem.

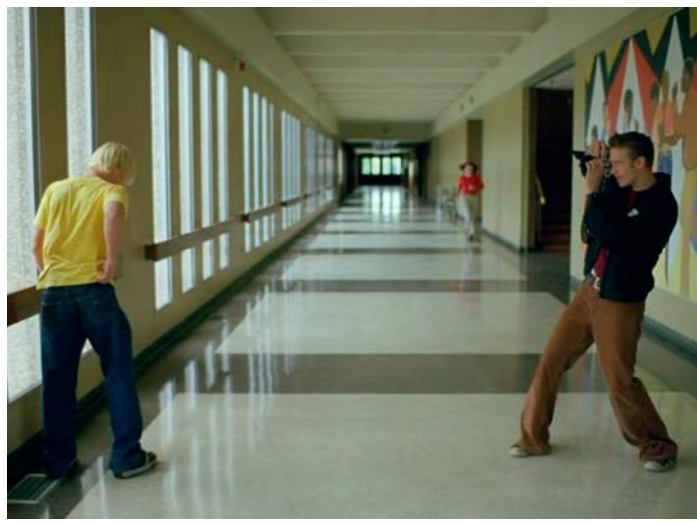

Figura 8

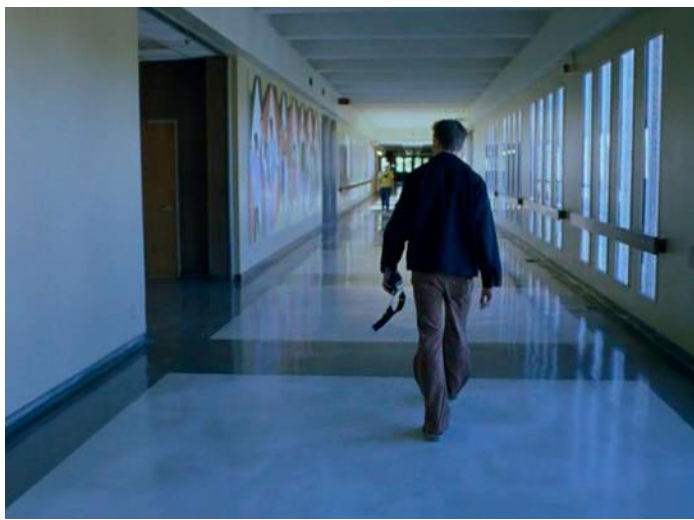

Figura 10

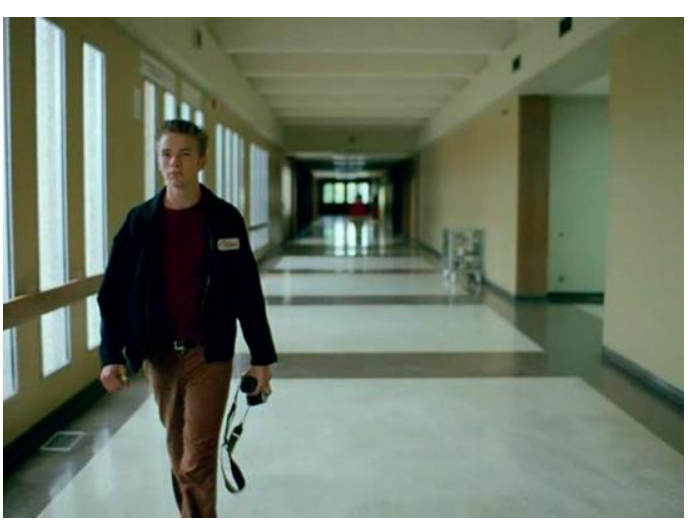

Figura 9

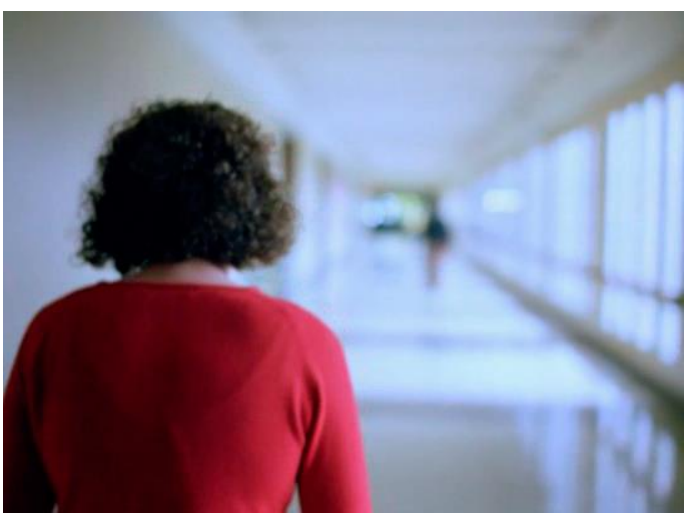

Figura 11

Peyrel (2003) atem-se aos sons que preenchem cada uma das sequências e afirma que, para além de um ponto de vista, essas cenas reproduzem verdadeiros 'pontos de escuta'. No 
primeiro caso, os sons guardam uma íntima conexão com a diegese - o barulho dos passos dos personagens, o disparar do obturador da câmera, o 'tapa' de John, que serve de sinal para que a foto aconteça, portas batendo, vozes, conversas -, embora alguns ruídos musicais (com destaque para uma flauta transversal) também se reproduzam, (de maneira pulverizada). Na segunda sequência, que responde inteiramente à perspectiva de Elias, esses sons musicais se intensificam, tanto antes quanto depois da pausa feita para o retrato, sobrepondo-se aos barulhos e ruídos da diegese, um pouco como se ecoassem da mente do fotógrafo. No terceiro momento, voltamos a ouvir a mesma música - mas de maneira já não tão proeminente misturada aos sons diegéticos, somados, agora, à respiração compassada de Michelle e aos sons do que se confirma ser um carrinho de biblioteca, que, com o avançar da sequência, veremos a moça conduzir na biblioteca. Há, no entanto, em meio a toda essa orquestração, um som presente em todas as cenas que se repete com a mesma exatidão nos três planos: o alarme da escola, anunciando a chegada dos assassinos e o advento de um novo tempo.

\section{CONSIDERAÇÕES}

Como buscamos demonstrar, a fragmentação é a principal estratégia escolhida por ambos os filmes para encenarem seus respectivos dramas. À medida que o tempo e o espaço tornam-se incertos e lacunares, a narrativa se desenrola como um novelo de linha emaranhado, revelando meadas para que o espectador as apanhe e possa, ele mesmo, desenredar a trama e urdir uma teia que dê conta de relacionar todos os personagens/núcleo de personagens, formando, por assim dizer, um só 'motivo'. Cada um desses 'fios' é relativamente autônomo, mas eles se entremeiam, se misturam, se cruzam e se separam, compondo, assim, a urdidura maior de sentidos que é o filme.

Se em Short Cuts essas relações parecem, de algum modo, mais tangíveis - uma vez que Altman nos faz adentrar a intimidade de cada um dos núcleos familiares e que os ecos do drama vivido em um núcleo preciso reverbera no outro -, em Elefante elas se dão de forma absolutamente efêmera, sem que consigamos apreender nada de realmente importante ou significativo desses adolescentes um tanto à deriva, sem passado nem futuro, aprisionados ao presente. Ambas as narrativas são 'costuradas', por assim dizer, pela morte, figura que parece assombrar e condicionar as duas histórias que vemos encenadas.

Dez anos separam um filme do outro. Se o trabalho de Altman marca a consolidação de um tipo de cinema cuja narrativa se desatrela de vez do modelo clássico, abrindo-se para a 
pluralidade de olhares e a complexidade das relações entre as imagens, a obra de Van Sant, parece, pois, tocar os limites dessa separação. Nele, o trabalho de elaborar sentidos cabe unicamente ao espectador, transformado, a exemplo dos personagens, em um sujeito também errante, convocado a construir seus próprios caminhos nesse espaço incerto desenhado pela escritura do filme.

Short Cuts e Elefante são obras que colocam em xeque o lugar do espectador a partir de uma estrutura narrativa que se (des)constrói frente a nossos olhos e que temos de reconstruir, como espectadores, munidos de nossas próprias ferramentas. Os dois filmes colocam em questão as noções de cinema narrativo, de realidade e, certamente, da própria condição humana, dividida entre a fragilidade da vida e a iminência da morte.

\section{REFERÊNCIAS BIBLIOGRÁFICAS}

BERNARDI, Sandro. Espace et Lieu dans le cinéma d'Antonioni. Revue Électronique du Centre d'études d'Arts Contemporains, Université Lille 3. DEMéter. Disponível em: $\langle$ http://demeter.revue.univ-lille3.fr/lodel9/index.php?id=115 $>$. Acesso em $11 \mathrm{de}$ abril de 2015.

DEBORD, Guy. A sociedade do espetáculo. Rio de Janeiro: Contraponto, 1997.

DEULEUZE, Gilles. Cinema I - A imagem-movimento. São Paulo: Brasiliense, 1985.

. Cinema II - A imagem-tempo. São Paulo: Brasiliense, 2007.

GAUDREAULT, André; JOST, François. A narrativa cinematográfica. Brasília: Ed. UNB, 2009.

PEYREL, Jêrome: Le croisement dans le couloir. Les lycéens au cinéma. Auvergne,2008/2009:<http://www.clermontfilmfest.com/03_pole_regional/lyceens08/elephant/accueil .html $>$. Acesso em 29 de abril de 2015.

ROSENBAUM, Johnathan. Blindsided. Chicago Reader. 7 de novembro de 2003. Disponível em: http://www.jonathanrosenbaum.com/?p=6101. Acesso em 26 de abril de 2015.

SARLO, Beatriz. Cenas da vida pós-moderna: intelectuais, arte e videocultura na Argentina. Rio de Janeiro: Ed. UFRJ, 1997.

SATURNINO, Céline. Le Dispositif cinématographique dans "Elephant" de Gus Van Sant. In: SCHEINFEIGEL, M. (Org.). Paroles Croisées: Aperçus théoriques sur les arts Univ. Paul Valéry Montpellier IV, Avril, 2005.

SERCEAU, Michel. Le jour où la terre tremblera. In: ROMANSKI, Philippe (Dir.). Lectures d'une oeuvre: Short Cuts, Raymond Carver - Robert Altman. Paris: Édition du temps, 1999, p. 165-181.

\section{Original recebido em: 22 de março de 2017 \\ Aceito para publicação em: 07 de novembro de 2017}

\section{Barbara Cristina Marques}

Professora de Teoria da Literatura do Departamento de Letras Vernáculas e Clássicas, da Universidade Estadual de Londrina. Docente do Programa de Pós-Graduação em Letras (PPGL), da Universidade Estadual de Londrina. Pesquisadora em Literatura, Cinema e Materialidades da Comunicação. 
Professor no curso de Cinema e Audiovisual na Universidade de Fortaleza. Docente e pesquisador do Programa de Pós-Graduação em Comunicação (PPGCOM) da Universidade Federal do Ceará. Pesquisador em Cinema, Estética e Psicanálise.

Esta obra está licenciada sob uma Licença Creative Commons. 